\title{
Prisoners Perceptions of a Mental Health Wellness Workshop
}

\section{Abstract}

Purpose: The aim of this paper is to report on the evaluation of a one-day mental health Wellness Workshop which was delivered to male prisoners in an urban prison in the Republic of Ireland.

Design: A mixed methods approach was used to evaluate the workshop. This paper presents the findings of the qualitative arm of the evaluation. Qualitative data were collected using semi structured telephone interviews with ten participants who had completed the programme.

Findings: The participants were overwhelmingly positive about the Wellness Workshop and the qualitative interviews articulated the ways that the workshop impacted on their ability to manage their own and other peoples mental health.

Originality/Value: As prisons attempt to limit the negative impact of prison life, implementing recovery orientated approaches such as the Wellness Workshop can have a positive impact on prisoners' mental health as well as raising their awareness and improving their attitudes towards mental distress and suicide. The concepts of self-help and peer support, espoused by the workshop offer a real opportunity to equip interested prisoners with skills to support themselves and other prisoners who are in distress.

Key Words: Prisoners mental health; Mental health promotion, Qualitative research, Evaluation, Wellness, Recovery.

\section{Citation}

Brian Keogh, Padraig McBennett, Jan deVries, Agnes Higgins, Marie O'Shea, Louise Doyle, (2017) "Prisoners perceptions of a mental health wellness workshop", International Journal of Prisoner Health, Vol. 13 Issue: 2, pp.8190, https://doi.org/10.1108/IJPH-03-2016-0008.

\section{Correspondence}

Brian Keogh, School of Nursing and Midwifery, Trinity College Dublin, 24 D'Olier Street, Dublin 2, Ireland. keoghbj@tcd.ie 


\section{Introduction}

Research findings have consistently shown that prisoners are vulnerable to developing mental health problems given the significant stressors associated with detention such as separation from family, overcrowding, lack of privacy, boredom, poor mental stimulation, long periods spent alone and fear of assault (Applebaum et al., 2001; Birmingham, 2003; Nurse et al., 2003; Frazer et al., 2009; Santoro et al., 2014). In addition, prisoners who have pre-existing mental health problems prior to detention are vulnerable to deteriorations in their mental health especially in those who have poorer coping skills (Applebaum et al., 2001; Birmingham, 2003). While there appears to be a direct link between serious mental illness and offending for a small number of people, other factors such as substance abuse and poor social supports may exacerbate risk factors (MacPhail and Verdun-Jones, 2013). Helping prisoners to manage their health as well as learning alternative thinking and behaviours has been advocated as one way of breaking the cycle of release and subsequent re-offense (Santoro et al., 2014). However, despite the high levels of mental distress within the prisoner population and their known vulnerability, there is inadequate service provision to meet demand and what services are available are under resourced (Nurse et al., 2003; Kupers, 2005). Prisoners need to be equipped with strategies to manage their mental health which not only assists their adaptation to prison stress, but supports positive approaches to successful reintegration on release (Frazer et al., 2009; Santoro et al., 2014). The aim of this paper is to report on the evaluation of a mental health Wellness Workshop which aimed to help participants understand and take responsibility for their mental health. The workshop was delivered to male prisoners in one urban prison in the Republic of Ireland by a voluntary organisation called 'Suicide or Survive' (SOS). This paper will focus on the qualitative findings of the evaluation.

\section{Mental Health and Mental Health Promotion in Prisons}

The topic of mental health has been widely studied among prison populations (Gore, 1999; Birmingham, 2003; Sirdifield et al, 2009). A number of studies have found a high incidence of mental illness amongst prisoners, with increased recognition of the higher prevalence of mental illness when compared to the general population (Brinded et al., 2001; Diamond et al., 2001; Hassan et al, 2011; Watson et al., 2004). Prisoners can experience mental health issues in varying degrees of severity, including depression, anxiety disorders and stress related symptoms (Graham, 2007; Fraser et al., 2009). In Ireland, the prevalence of psychosis amongst Irish prisoners was found to be significantly higher than other countries (Flynn et al., 2012). Additionally, in Irish prisons, between $60 \%$ and $80 \%$ of prisoners were found to have a substance abuse problem (Kennedy et al., 2004) and as entering prison 
necessarily means a cessation of illicit drug use, the experience of withdrawal can also increase mental distress.

Prison is also regarded as a high-risk environment for suicide and self-harm with high distress levels and increased risk of suicide associated with initial custody periods (Gullone et al., 2000; Shaw et al., 2004; WHO, 2007; Hassan et al., 2011). Recent research suggests that between $5-6 \%$ of male prisoners and $20-24 \%$ of female prisoners self-harm every year (Hawton et al., 2014). In addition it is reported that the suicide rates of prisoners are significantly higher than the general population in many countries (Fazel et al., 2011). A number of factors influence this including the fact that even before incarceration prisoners are a vulnerable population at high risk of self-harm and suicidal behaviour (Konrad et al., 2007). Prisons contain a high number of young males who are socially disenfranchised with poor levels of education and high levels of unemployment (Seymor, 2010). In addition, many factors around the act of incarceration can impact negatively on a person's mental health. The protective effect of having close friends and family members to confide in and to offer support is largely lost in the prison setting where access to family and friends is significantly decreased (MacNamara and Mannix-McNamara, 2014). The stress associated with incarceration and the prospect of a long prison sentence can have a significant psychological impact on a person. This psychological impact is increased when the person is serving a life sentence (Patton and Jenkins, 2005). Despite the fact that prisoners are a recognised high risk group for suicide and self-harm, and that they receive a mental health examination upon their arrival to prison; many prisons do not have adequate mental health services to meet the identified mental health needs of prisoners.

Mental health promotion in prisons has also been perceived to be 'under-resourced' (Carager et al., 2000; Watson et al., 2004). In 2007, The Trencin Statement on Prisons and Mental Health was ratified at the WHO International Meeting on Prisons and Health in Slovakia (WHO, 2008). It suggests that there is an urgent need to provide additional support to prisoners experiencing mental health problems. It further states that it is imperative that prisoners be "adequately prepared for re-settlement" when they return to their community. One Trencin Statement recommendation is that community services and in-prison services develop strong relationships to ensure a successful reengagement with the community for the majority of prisoners. The concept that mental health promotion should be conducted within the prison setting, working in tandem with other aspects of rehabilitation is not a new one; however is deemed to be poorly understood and under-resourced in many cases (Carager et al., 2000, Watson et al., 2004; WHO 2007). 


\section{The Wellness Workshop}

The one day Wellness Workshop, the focus of this paper, is designed and delivered by an organisation called 'Suicide or Survive' (SOS). Suicide or Survive is a registered charity in Ireland and their aims include a commitment to reducing the stigma attached to mental illness and the provision of educational and therapeutic programmes to prevent and raise awareness about suicide and other mental health issues. The Wellness Workshop was developed by SOS in response to a number of key issues. One of these issues was the need to prevent un-wellness and enable people to look after their own mental health. The idea for the Wellness Workshop grew from the belief that people can learn to stay well by learning certain strategies and preventative measures. The Wellness Workshop aims to do this by encouraging participants to take personal responsibility for their own mental health and to identify not only what 'triggers' mental health difficulties but also crucially what keeps people well. The ultimate hope is that if all people are educated to look after their mental health then when issues around hopelessness and negative thinking surface they will have the skills to monitor and evaluate their own wellness and seek appropriate support (Doyle et al., 2016). The Wellness Workshop is delivered over one day in an atmosphere of genuine warmth and caring where participants are encouraged to actively participate and learning is carried out in a manner that blends fun and serious learning. They are normally facilitated by three individuals who are a combination of mental health professionals and people with lived experience of mental distress and combine practical tools and tips with personal testimony of hope and recovery. Areas included in the workshop are relaxation and stress management, the relationship between thoughts and emotions, the development of a wellness toolkit and daily wellness plans. The workshop has been delivered to the general public and have been evaluated positively (Doyle et al., 2016). In 2012, an opportunity emerged for SOS to deliver the Wellness Workshops in a large urban medium secure prison for men in Ireland. The authors of this article were commissioned to evaluate the Wellness Workshop, including the workshop delivered to prisoners. While the authors completed a mixed methods approach, only the qualitative data are presented here. The initial response rates for the surveys among the prison population were promising $(n=69)$ however response rates for post and particularly follow up surveys were not as successful which meant that it was not possible to compute meaningful results. The initial survey was administered at the end of the Wellness Workshop, which probably influenced the relatively high response rate at that time which was difficult to sustain at post and follow up. 


\section{The Study}

\section{Aim of Evaluation}

The aim of the study was to evaluate the effect of the Wellness Workshop on participants' knowledge of mental health, their attitudes towards mental illness and suicide, and their ability to recognise mental distress in themselves and others. In addition the evaluation sought to establish if attending the workshop led to the use of a repertoire of strategies to manage mental distress.

\section{Design}

The qualitative findings presented here form part of a longitudinal evaluation which employed a mixed methods approach to evaluate the Wellness Workshop delivered to the prison population. The qualitative data were collected using semi structured telephone interviews following completion of the main survey and participants who wished to take part in interviews were required to complete an opt-in form separate to the questionnaire. Telephone interviews provided both the participants and the researchers with a more flexible approach than face-to-face interviews given the complexities associated with accessing and recruiting members of the prison population. Access to the prison population was negotiated through the Prison Governor and a prison warden was responsible for coordinating the prisoner's participation in the study. The interviews were completed three months after the attendance at the initial workshop. All the prisoners who expressed an interest in being interviewed were contacted through the gatekeeper and a mutually agreed time for conducting the interviews were arranged. A semi-structured interview guide was developed by the research team and the interviews were conducted by one member of the team. The interviews focused on exploring in more depth the participant's perceptions of the workshop and eliciting specific examples of how they used the techniques taught during the workshop in their daily lives. Ethical approval to conduct the study was granted from the Trinity College, Faculty of Health Science's Research Ethics Committee and from the Irish Prison Service Prisoner-Based Research Ethics Committee.

\section{Data Analysis}

Qualitative data from the telephone interviews were recorded and transcribed verbatim. Each interview was about 20 - 30 minutes long. Using a thematic approach guided by Braun and Clarke (2006), interview transcripts were read and reread and an initial coding framework was established. The interviews were coded and categorised against the coding framework and a number of potential themes emerged. This involved the use of a thematic map as suggested by Braun and Clarke (2006) which identified the relationships between codes, sub-themes and overarching themes. This was an iterative approach and the themes 
were continually refined until the final themes were defined and named. To enhance the rigour of the process, two researchers were involved in the coding and categorisation process. In addition a third researcher reviewed the analytic process to confirm the emerging themes. A total of four workshops with 84 participants were conducted from which ten prisoners volunteered to be interviewed. Their ages ranged from 19 to 47, their average age was 31.9. Five themes emerged from the data and are discussed in more detail in the next section.

\section{Results}

\section{Managing Mental Health within the Prison Environment}

Prison life was described in different ways by the participants, for some it was monotonous while for others it was described as unpredictable. All of the participants spoke about how stress was a major problem in prison and most of the participants reacted to stress in an angry or aggressive way such as smashing up their cell or damaging prison property. The participants' reiterated the commonly held belief that men find it difficult to talk about their feelings and are required to present a tough outer exterior. This was heightened in prison and the participants described a world where one had to be tough and any signs of weakness were to be avoided at all cost. However, throughout the interview transcripts there was a sense that the participants felt vulnerable in prison and when this vulnerability was juxtaposed with the participants perceived necessity to be tough, it created a tension that was a challenge for them. Any outward display of what they described as weakness was not an option for the participants and this impacted on their ability and their desire to speak openly about how they were feeling and their experiences of mental distress. These points are exemplified in the following quotation:

'When I was outside [prison] I'd have time to think and say don't react like that but in here you have to wear a mask. You can't turn around to someone on the landing and say 'well hang on let's think about this. How are you feeling about that and this is how I'm feeling about it.' It doesn't happen in here. And the thing in here is that you can't be seen to run away like because then my understanding of it is that you'll be walked all over because that will be the thing that will happen to you all the time' [p28].

Because of this desire to project a tough outward appearance, this impacted on whom the participants could talk to when they were feeling stressed. Some of the participants had relatives who were also in prison and these proved as valuable sources of support when required. Without these relatives, the participants suggested that it would be very hard to find anyone to confide in. Participants who didn't have close friends or relatives in prison 
described having no one to talk to and described feeling isolated. Prison officers were not perceived as someone that the participants could confide in as there were fears about confidentiality and that the participants' feelings and experiences might be inappropriately divulged. A listening service provided by prisoners for prisoners was available and the participants were aware of its existence. This service was delivered by specially trained prisoners who were available to others who needed someone to talk to in times of distress. While the service was seen as necessary and beneficial, there was recognition that it was not a professional service and did not offer advice, counselling or other interventions beyond listening and impartiality. Off the ten participants who agreed to be interviewed, six of them described themselves as people who had self-experience of mental distress. These issues ranged from drug and alcohol problems to anxiety, depression and self-harm. Some of the participants were accessing mental health services in prison such as counselling. However, in terms of professional help, this was perceived as difficult to access and services such as counselling could not be accessed immediately and often were associated with waiting lists. Visits and telephone calls were the participants' only connection to the outside world and as such were another valuable source of support. However, visits and telephone calls were often an additional source of stress that caused feelings that needed to be managed. For example, one of the participants found that he was preoccupied about his children outside prison. This was worsened when they visited and the children were often upset and distressed when they were leaving. There was recognition that suicide was a problem for people in prison, especially for men. However, there was a perception that improvements had been made which had reduced the rate of suicide. Despite this, there was a suggestion that suicidal feelings and thoughts were prevalent throughout the male prison population. Overall, the participants described prison life as tough with many stressors impacting negatively on their daily lives. The participants spent long periods of time alone and had, what they described as 'a lot of time on their hands' and were anxious to fill this time in a productive way.

\section{Perspectives of the Wellness Workshop: Motivations for Attending, Expectations and Overall Experience}

The chaplaincy service at the prison was instrumental in letting people know about the Wellness Workshop and many of the participants were encouraged to attend through their contact with this service. However prison officers and other inmates also spread the word about the workshop and participants became interested in attending when they heard positive reports from other attendees. A number of the participants had done the course more than once and this suggests that they either really enjoyed and valued the course or that they used it as an avenue to escape the routine and monotonous nature of prison life. 
As mentioned, the participants spoke about the amount of time they had on their hands in prison and that some of them used courses such as the Wellness Workshop to either help the time pass as well as to better themselves at a personal level. Two of the participants specifically stated that they wanted to attend the wellness workshop because they wanted information about mental health and to learn strategies to help manage their emotions.

'It's a combination of a lot of them I suppose. The reason I got into this is because my emotions put me into prison. I couldn't manage my emotions so my emotions managed me and they led me then to taking a life in a rage. So I led my life to do a life sentence so I've seen beyond that now and I manage my own mental health quiet well now and I'm happy with that. From all my teaching and the course and that I've picked up. I suppose if I see anything on mental health I'm all over it you know I want to know if there is more to be picked up and more to be learnt.' [p25]

\section{Overall Experiences of the Wellness Workshop}

The response to the workshop from the participants was overwhelmingly positive and throughout the transcripts the participants consistently praised the workshop and the facilitators. There was tremendous respect for the facilitators and they were seen as brave for coming into the prison environment, opening up about their experiences and sharing their stories. The approach used in the workshop to learn about mental health was highly regarded and valued by the participants. There was a sense that a different approach to the workshop might not have been as successful in getting the message of hope and recovery to the participants. Specifically, hearing about other peoples' experiences of mental distress and how they were able to manage this distress was crucial in helping the participants to understand the key messages associated with the workshop and helping them to consider their own mental health in a different light.

'What I can remember most about the workshop is the lady, [name]. Her story like she had her story up on the screen about mental health, and you'd think you'd see a woman like that and never in a million year think that that woman had the problems that she had. It was great listening to her story because it makes you stop and think that if a woman like that who's just full of life.' [p34]

Apart from the facilitators sharing the stories, some of the participants described other features of the wellness workshop that they enjoyed learning about such as the mindfulness minute. However there was a lack of emphasis during the interviews on specific aspects of the workshop that they enjoyed and the participants were more likely to praise the workshop in its entirely rather than focusing on specific components. This suggests that the overall value of the workshop was in the creation of an atmosphere where the participants were free to learn about their mental health in a safe and welcoming environment. This environment was not just created by the facilitators but also by the other participants who shared their own stories and experiences as well. 


\section{Applying the Principles of the Wellness Workshop - Managing the Stresses of Prison Life}

As mentioned, the participants described prison life as being very stressful and that stress was something that many of the participants had difficulty managing. Following attendance at the wellness workshop, all of the participants spoke about how the strategies they learned in the wellness workshop helped them to manage the stress associated with prison. In addition there were also instances where the participants described helping others to manage their mental health and wellbeing either within the prison population or within their extended social network. Many of the participants appeared to take a more reflective approach to problems and were more inclined to look for the root problems and reach a resolution rather than to react to stress in either an angry or aggressive way. From the transcripts it could be interpreted that the principles and strategies that the participants learned equipped them with specific skills to manage the many stresses they encountered on a daily basis. More importantly, these skills were used against the backdrop of the participants having a generally better knowledge of mental health. Therefore, the practical application of the strategies was effective because the participants appeared to have a more positive attitude towards mental health and a greater belief in their control over situations. In addition, there was a greater desire to recognise stress, examine alternative ways of coping and to avoid confrontations that often exacerbated how the participants were feeling. This new approach to managing stress is exemplified in the following quotation:

'Before I went into that course I thought that there was something wrong with
me because of my anger. When I'm in an argument with somebody or if I get
into a small argument with someone I usually kick off and I'd do stupid things
but ever since that course I've learned how to control my breath and control the
situation I'm in and look at the outcome. If I was going to do something stupid
just look past the thing that I was going to do and try to see what's going to
happen to you and what the consequences are.'[p31]

In terms of the specific strategies that the participants used, the most talked about was the breathing techniques that were used to control their stress and to manage their anger. The participants described using deep breaths to help them manage stress and to help calm themselves down. Another strategy that the participants talked about was the mindfulness minute. While some of the participants didn't mention the mindfulness minute by name, there were many instances where they described using it to take some time out and to manage their stress in a more productive way.

Other strategies such as the 'wheel of life' and thinking positive thoughts were talked about by the participants albeit less frequently. In addition, the workshop helped the participants' to think creatively about the different ways that they could help to manage what were 
sometimes referred to as 'bad thoughts' such as letter writing and listing all the positive things that the participants had.

'I told you that I was always thinking about my family and my wife on the outside. So they told me if something like that comes to my mind then I should maybe do something different like write letters or try to think something positive like how good of a relationship I have with my wife. I should definitely think of something that would make me happy and give my attention to that thinking. So I tried these, like yesterday I wrote a letter and I wrote four pages about my kids and stuff like that until I fell asleep.' [p29]

There was also some discussion in the transcripts about how the participants' used what they learned in the workshop to help other people who were having difficulties. In one incident, the participant described how he uses the 'Wheel of Life' in his interactions with other prisoners through his work in the listening service. In another incident, the participant described how attending the wellness workshop gave him the confidence to talk to someone who was experiencing distress. In this example, the participant described retelling [facilitators name] story to a friend of his in prison and how he believed that this was helpful for this particular individual.

\section{Participants Perceptions of Mental Distress and Suicide following Attendance at the Wellness Workshop}

There was some evidence in the transcripts that might suggest that the participants' attitudes towards mental distress and suicide improved following attendance at the wellness workshops. The most prominent attitudinal change cited was the belief that mental distress could affect anyone regardless of his or her background, situation or walk of life. There were also some references to the participants' attitudes towards suicide in particular how they had an improved understanding of why someone might want to consider suicide as an option. In particular how difficult it is to talk about suicide and also how talking about suicidal feelings and feelings generally are key to preventing people dying by suicide. In addition, two of the participants mentioned that prior to attending the workshop they believed that suicide was a selfish act. While this perception has not changed for one of the participants, the other felt that following the workshop, he had a better understanding of the concept and that he would be in a better position to talk to people who were in distress and considering suicide.

'Before I used to say that they'd be selfish and not thinking about it but then people don't think about other people, they just think about ending their lives. It's hard to talk about but now I can talk about it. I've never tried to harm myself but people that have tried; it's very hard for them to come in to someone. But l'd just sit there and talk to them saying that it's not worth it and all of that.' [p33] 


\section{Discussion}

The aim of this study was to evaluate a mental health Wellness Workshop which was delivered to prisoners in one urban medium secure prison in the Republic of Ireland. While the experiences of the participants were mostly positive, there were some criticisms of the workshop and these mainly centred on the amount of information that was delivered during the day and the location of the workshop. In addition, the participants felt that some of the other workshop attendees were disinterested and this detracted from the overall experience of those who were motivated to attend. Furthermore, the participants offered some suggestions for improvement including extending the workshop to all prisons especially young offender units. While the qualitative findings here support the use of the Wellness Workshop as a mental health promotion activity in prison, further research which is able to measure sustained impact overtime is essential. Innovative strategies to explore interventions such as these need to be designed in order to convince policy makers that mental health promotion strategies like this one need to be supported and funded. While there are many studies exploring prisoners' mental health, access and recruitment issues can be difficult and time consuming (Kupers, 2005; Maruca and Shelton, 2015) which may compromise response rates as in this study. However, research has clearly highlighted the challenges that prison life has on prisoner's mental health. There is therefore significant potential for interventions which aim to improve and maintain wellbeing in the prison setting. Indeed it has been suggested that the prison setting provides a promising opportunity to have an impact on the lives of those who are hardest to reach (Fraser, 2009).

According to Brooker et al (2007) effective mental health care starts with identifying those who are in need of support. While physical and mental health assessments are conducted in Irish prisons (Kennedy et al., 2004) identification of those vulnerable to and with mental health problems lacks usefulness when appropriate services or support cannot be provided. Furthermore, interventions rely heavily on the medical approach to mental distress (MacNamara and Mannix-MacNamara, 2014) which tends to see psychopharmacology as the primary mode of intervention. The provision of health care including mental health care within the Irish Prison Service is described as evolving and opportunities for health promotion have been recognised (Health Services Executive, 2009). Some progress has been made in identifying mental health problems in those prisoners who are on remand and focus on diverting them away from mainstream prison services to mental health services (Mclnerney et al., 2013). However, these services do not capture those who are currently prisoners or who may be vulnerable to developing mental health problems. This further highlights the need for innovative mental health promotion strategies within prisons. In the delivery of the Wellness Workshop in prison there were no changes made to its content or 
format as it was perceived that the workshop had a universal message of wellness that was applicable regardless of the background or context of the participants (Doyle et al., 2016). Given the participants descriptions of their experiences in prison and the well-documented impact that prison life can have on mental health, bespoke workshops which target specific concerns may be warranted. For example, many of the participants spoke about managing anger as a specific problem. In addition, some of the criticisms and suggestions for improvement made by the participants could also be considered. De Viggiani (2007) provides considerable detail about how prison life can have a detrimental effect on the mental and emotional wellbeing of prisoners and on their ability to cope within a paternalistic and authoritarian regime. While changes to the structural environment of the prison will be far more effective in terms of improving prisoner mental health, it is unlikely that these will occur given the competing demands on the public purse. Therefore tailor made, cost neutral and well evaluated mental health promotion initiatives may go some way to helping prisoners to manage the negative impact of prison. Furthermore, strategies that aim to prevent or minimise the emergence or impact of mental distress and to improve attitudes to mental distress need to be promoted within a system where help seeking behaviours are traditionally low and where there is reluctance to talk openly about mental distress (Skogstad et al., 2006).

The Wellness Workshop presented many prisoners with the first real opportunity to think about their mental health and wellbeing. The participants identified how they were able to use the simple but effective strategies that they learned about during the workshop to respond to stress and to explore alternative ways of coping. In particular, strategies such as mindfulness and breathing techniques were found to be particularly helpful. In addition, the context of the workshop delivered in an environment of hope and mutual respect resonated strongly with the participants. These approaches confirm the usefulness of recovery orientated strategies and demonstrate their effectiveness when the principles are applied regardless of the environment. Recovery orientated strategies aim to conceptualise mental distress within a more positive framework and seeks to empower individuals to manage their own mental health within a philosophy of self-help. As a concept, mental health recovery has, over the last number of years, underpinned mental health policy in many countries (Lakeman, 2010; Slade et al., 2014) but generally within community or non-secure mental health environments. The prevalence of mental distress within the prison system suggests that services offered to prisoners should mirror mainstream services (Health Services Executive, 2009), therefore, their philosophy should be underpinned by recovery orientation set within a secure environment. Indeed, McKenna et al (2014) provide some evidence of 
how recovery orientated approaches within a forensic setting are beginning to take shape in an environment that typically favours safety, security and biomedical approaches. While custodial priorities will always shape the delivery of the prison services in Ireland and elsewhere, prisons will need to be able to manage the mental distress that exists while also reducing the harm that prison exerts on prisoners mental health (Frazer et al., 2009). While more appropriate responses to mental distress in prisons has been advocated by the World Health Organisation (2008) and some improvements have been achieved, progress is still required. Recovery orientated approaches which emphasise attitudinal changes, mutual respect and dignity and are underpinned by peer and self-help offer an opportunity for improved responses to mental distress within the prison system.

\section{Conclusion}

The findings presented here about the Wellness Workshop delivered in the prison setting has been evaluated as a very positive initiative for the prisoners who took part in the research interviews. However, these findings need to be couched within a number of limitations. While the telephone interviews yielded remarkable insights into the prisoners' experiences of the workshop, opportunities for face to face interviews may have helped the researchers to evaluate its impact more comprehensively and to further support its use. In addition, given the small sample size, the findings are not generalizable. Furthermore, the participants' positive experiences of the workshop may have influenced their decision to take part in the interviews. A number of prisoners identified how the workshop helped them to help other prisoners and members of their families and friends. In light of this, the workshop offers a real opportunity to equip interested prisoners with skills to support other prisoners who are in distress. Currently, another recovery oriented approach, namely Wellness Recovery Action Plan (WRAP) which builds on and supports the Wellness Workshop is being introduced. These have been well evaluated in other contexts (Higgins et al., 2012). In addition, prison officers have also attended the Wellness Workshop. It is imperative that evaluative strategies are conceptualised to capture the impact of these innovations and their sustainability over time. Given the fluctuating nature of prison populations, innovations such as these also need to consider the impact of prisoner release and other factors in the implementation, maintenance and sustainability of mental health promotion strategies within the prison context.

\section{Acknowledgement}

This evaluation was funded by a grant from Suicide or Survive and the National Office for Suicide Prevention, Ireland. The authors declare no conflict of interests. 


\section{References}

Appelbaum, K., Hickey, J. and Pracker, I. (2001), "The role of correctional officers in multidisciplinary mental health care in prisons", Psychiatric Services, Vol. 52, pp. 13431347.

Birmingham, L. (2003), "The mental health of prisoners", Advances in Psychiatric Treatment, Vol. 9, pp. 191-201.

Braun, V. and Clarke, V. (2006), "Using thematic analysis in psychology", Qualitative Research in Psychology, Vol. 3, 77-101.

Brinded, P.M., Simpson, A.I.F., Laidlaw, T.M., Fairley, N. and Malcolm, F. (2001), "Prevalence of psychiatric disorders in New Zealand prisons: a national study", Australia and New Zealand Journal of Psychiatry, Vol. 35, pp. 166-73.

Brooker, C., Sirdifield, C. and Gojkovic, D. (2007), Mental Health Services and Delivery: An Updated Review, Criminal Justice and Mental Health Research Group, University of Lincoln.

Carager, M., Dixon, P., Bird, L., Hitchman, C., McGough, H. and Carr-Hill R. (2000), The Range and Quality of Health Promotion in HM Prisons, King's Fund and Prison Health Policy Unit, London.

de Viggiani, N. (2007), "Unhealthy prisons: exploring structural determinants of prison health", Sociology of Health \& IIIness, Vol. 29. No. 1, pp. 115-135.

Diamond, P. M., Wang, E. W., Holzer, C. E., Thomas, C. and des Cruser, A. (2001), "The prevalence of mental illness in prison", Administration and Policy in Mental Health, Vol. 29, pp. 21-40.

Doyle, L., O'Shea, M., Keogh, B., De Vries, J., McBennett, P. and Higgins, A. (2014), Wellness Workshop Longitudinal Evaluation Report, Trinity College Dublin, Dublin.

Doyle, L., de Vries, J., Higgins, A., Keogh, B., McBennett, P. and O'Shea, M. (2016), "A mixed methods longitudinal evaluation of a one-day mental health wellness intervention", Health Education Journal, published online before print August 26, 2016, doi: 10.1177/0017896916662075.

Fazel, S., Grann, M., Kling, B. and Hawton, K. (2011), "Prison suicide in 12 countries: an ecological study of 861 suicides during 2003-2007", Social Psychiatry and Psychiatric Epidemiology, Vol. 46, pp. 191-195.

Flynn, D., Smith, D., Quirke, L., Monks, S., Kennedy, H.G. (2012), "Ultra high risk of psychosis on committal to a young offender prison: an unrecognised opportunity for early intervention", BMC Psychiatry, Vol. 12. Available at http://www.biomedcentral.com/1471$244 \mathrm{X} / 12 / 100$.

Fraser, A., Gatherer, A., and Hayton, P. (2009), "Mental health in prison: great difficulties but are there opportunities?", Public Heath, Vol. 23, pp. 410-414.

Gore, S. M. (1999), "Suicide in prisons: Reflection of the communities served, or exacerbation of risk?", British Journal of Psychiatry, Vol. 175, pp. 50-55.

Graham, L (2007), Prison Health in Scotland: A Health Care Needs Assessment, Scottish Prison Service, Edinburgh. 
Gullone, E., Jones, T. and Cummins, R. (2000), "Coping styles and prison experience as predictors of psychological well-being in male prisoners", Psychiatry, Psychology and Law, Vol. 7, pp. 170-181.

Hassan, L., Birmingham, L., Harty, M.A., Jarrett, M., Jones, P., King, C., et al. (2011), "Prospective cohort study of mental health during imprisonment", British Journal of Psychiatry, Vol. 198, pp. 37-42.

Hawton, K., Linsell, L., Adeniji, T., Sariaslan, A. and Fazel, S. (2014), "Self-harm in prisons in England and Wales: an epidemiological study of prevalence, risk factors, clustering, and subsequent suicide", The Lancet, Vol. 383, No. 9923, pp. 1147-1154.

Health Service Executive, Nursing and Midwifery Planning \& Development and Irish Prison Service (2009), Nursing in the Irish Prison Service: Working Together to Meet the Healthcare Needs of Prisoners, HSE, Dublin.

Higgins, A., Callaghan, P. de Vries, J., Keogh, B., Morrissey, J., Nash, M., Ryan, D. Gijbels, H. \& Carter, T. (2012) "Evaluation of mental health recovery and Wellness Recovery Action Planning education in Ireland: a mixed methods pre-post evaluation", Journal of Advanced Nursing, Vol. 68, pp, 2418 - 2428.

Kennedy, H.G., Monks, S., Curtin, K., Wright, B., Linehan, S., Duffy, D., Teljeur, C. and Kelly, A. (2004), Mental Illness in Irish Prisoners Psychiatric Morbidity in Sentenced, Remanded and Newly Committed Prisoners, National Forensic Mental Health Service, Dublin.

Konrad, N., Daigle, M. S., Daniel, A. E., Dear, G. E., Frottier, P., Hayes, L. M., Kerkhof, A., Liebling, A., and Sarchiapone, M. (2007), "Preventing suicide in prisons, part 1: Recommendations from the International Association for Suicide Prevention Task Force on suicide in prisons", Crisis, Vol. 28, No. 3, pp. 113-121.

Kupers, T. (2005), "Toxic masculinity as a barrier to mental health treatment in prison", Journal of Clinical Psychology, Vol. 61, No. 6, pp. 713-724.

Lakeman, R. (2010), "Mental health recovery competencies for mental health workers: a Delphi study", Journal of Mental Health, Vol. 19, No. 1, pp. $55-67$.

MacPhail, A. and Verdun-Jones, S. (2015), Mental IIIness and the Criminal Justice System, International Centre for Criminal Law Reform and Criminal Justice Policy, Montreal.

Maruca, A. and Shelton, D. (2015), "Addressing methodological issues in correctional health research: A case report”, Journal of Forensic Nursing, Vol. 11, No. 2, pp. $118-120$.

Mclnerney, C., Davoren, M., Flynn, G., et al. (2013), "Implementing a court diversion and liaison scheme in a remand prison by systematic screening of new receptions: a 6 year participatory action research study of 20,084 consecutive male remands", International Journal of Mental Health Systems, Vol. 7, No. 18, doi: 10.1186/1752-4458-7-18.

MacNamara, C. and Mannix McNamara, P. (2014), "Placing the promotion of health and wellbeing on the Irish prison agenda: The complexity of health promotion in Irish prisons", Irish Journal of Applied Social Studies, Vol. 14, No. 1, pp. 49-59. 
McKenna, B., Furness, T., Dhital, D., Park, M. and Connally, F. (2014), "The transformation from custodial to recovery-oriented care: A paradigm shift that needed to happen", Journal of Forensic Nursing, Vol. 10, No. 4, pp. $226-233$.

Nurse, J., Woodcock, P., and Ormsby, J. (2003), "Influence of environmental factors on mental health within prisons: focus group study", British Medical Journal, Vol. 327, pp. 327 480.

Paton, J. and Jenkins, R. (2005), "Suicide \& suicide attempts in prison". In Hawton, K. (Ed), Prevention \& Treatment of Suicidal Behaviour, Oxford University Press, Oxford, pp. 307-334.

Santora, L. Arild-Espnes, G. and Lillefjell, M. (2014), "Health promotion and prison settings", International Journal of Prisoner Health, Vol. 10 No. 1, pp. 27 - 37.

Seymour, L. (2010) Promoting and Protecting Offenders Mental Health and Wellbeing, Centre for Mental Health, London.

Shaw, J., Baker, D., Hunt, I.M., Moloney, A. and Appleby, L. (2004), "Suicide by Prisoners: National Clinical Survey2, British Journal of Psychiatry, Vol. 184, pp. 263-267.

Sirdifield, C., Gojkovic, D., Brooker, C. and Ferriter, M. (2009), "A systematic review of research on the epidemiology of mental health disorders in prison centres: A summary of findings", Journal of Forensic Psychiatry and Psychology, Vol. 20, No. 1, pp. 78-101.

Skogstad, P., Deane, F. and Spicer, J. (2006), "Social-cognitive determinants of helpseeking for mental health problems among prison inmates", Criminal Behaviour and Mental Health, Vol 16, pp. 43-59.

Slade, M., Amering, M., Farkas, M., Hamilton, B., O'Hagan, M., Panther, G., Perkins, R., Sherpherd. G., Tse S. and Whitley, R. (2014), "Uses and abuses of recovery: implementing recovery orientated practices in mental health systems", World Psychiatry, Vol. 13, pp.12 20.

Watson, R., Stimpson, A. and Hostick, T. (2004), "Prison health care: a review of the literature", International Journal of Nursing Studies, Vol. 41, No. 2, pp. 119-128.

World Health Organisation (2007), Health in Prisons: A WHO Guide to the Essentials in Prison Health, WHO, Copenhagen.

World Health Organisation (2008), Trencin Statement on Prisons and Mental Health, WHO, Copenhagen. 